$1 N-20$

NASA Contractor Report 189059

6236)

p $q$

\title{
NEP Mission Sensitivities to System Performance
}

James H. Gilland

Sverdrup Technology, Inc.

Lewis Research Center Group

Brook Park, Ohio

December 1991

Prepared for

Lewis Research Center

Under Contract NAS3-25266

\section{N/SA




\title{
NEP MISSION SENSITIVITIES TO SYSTEM PERFORMANCE
}

\author{
James H. Gilland* \\ Sverdrup Technology, Inc. \\ Lewis Research Center Group \\ Brook Park, Ohio 44142
}

\begin{abstract}
Nuclear Electric Propulsion (NEP) mission performance is strongly affected by system performance. Power and propulsion system specific mass, specific impulse, and efficiency all combine to determine the performance limits for a given mission. Thruster technology determines the specific impulse and efficiency of the system. The effects of these parameters on the mission performance of NEP systems relative to other concepts has been analyzed to give guidance to thruster development goals for a range of missions: Lunar Cargo, Mars Cargo, and Mars Piloted. Mission sensitivities to system parameters are discussed, and technology requirements are identified for each mission.
\end{abstract}

\section{INTRODUCTION}

Trajectory calculations and mission analyses of electric propulsion vehicles are highly complex. The low vehicle acceleration characteristic of these vehicles require extended if not continuous acceleration throughout the trajectory. Low thrust mission analysis must therefore assess the full, integrated path of the vehicle. The exact optimum trajectory path for a given vehicle is determined by the system parameters of the vehicle, which determine the externally imposed accelerations. Changes in propulsion system performance, when integrated over the entire mission trajectory, can have dramatic impacts upon vehicle performance in terms of trip time or initial mass requirements. The propulsion system performance parameters are thus closely meshed with the mission performance results.

Propulsion system parameters can be defined as

System Specific Mass $(\alpha)$ - ratio of power/propulsion system mass to electric power input to thrusters - $\mathrm{kg} / \mathrm{kWe}$,

Specific Impulse $\left(\mathrm{I}_{\mathrm{sp}}\right)$ - Thrust per unit propellant weight flow, or exhaust velocity divided by $\mathrm{g}_{\mathrm{o}}$ - seconds, and

Propulsion System Efficiency $(\eta)$ - Conversion efficiency from clectric to exhaust power - dimensionless.

Mission parameters that must be specified are

Destination - Target planets, Round trip or one way;

Trip Time; and

Payload.

To first order, these parameters can serve to characterize electric propulsion system performance capabilities (Jones and Monck 1984).

A typical approach to electric propulsion mission analysis has been to assume the performance capabilities of power systems and electric thrusters, and to optimize the mission based on these fixed parameters. This approach gives results of interest to mission planners assessing the utility of certain technologies; however, technology developers receive little or no guidance as to what performance goals should be selected in their research. The study presented herein is aimed at showing the sensitivity of mission performance to each of the three systems variables described above, with no assumptions of specific power system or thruster system technology or performance. Instead, the results are intended to identify an envelope of performance within which electric propulsion technologies 
must operate for significant gains in mission performance.

\section{MISSION SENSITUYITY ANALYSIS}

Three missions have been considered for application of Nuclear Electric Propulsion (NEP) systems: Lunar Cargo, Mars Cargo, and Mars Piloted. These missions have been selected to span the range of mission requirements identified for the Space Exploration Initiative; some conclusions can be drawn pertaining to other NASA missions such as orbital transfer or robotic planetary probes. Mission requirements range from the mass efficient transportation of cargo with no emphasis on trip time (cargo missions), to the transportation of small payloads in minimum trip times (piloted missions). The differences in mission figures of merit and trajectory analysis among the three missions requires a different approach for each.

\section{Lunar Cargo}

The lunar cargo mission is essentially an Earth orbital transfer mission. As such, the NEP trajectory follows the familiar spiral path, gradually increasing orbital altitude with increasing vehicle tangential velocity. The mission assumptions used for this study are a round trip cargo mission to Low Lunar Orbit (LLO) from a Low Earth Orbit of $\sim 500 \mathrm{~km}$. Because of the relative magnitudes of the vehicle acceleration and the Earth's gravity, the trajectory requirements may be approximated by a constant $\Delta V$ value of $8 \mathrm{~km} / \mathrm{s}$ each way (Palaszewski 1989). The NEP system may then be optimized analytically for maximum payload fraction (Auweter-Kurtz et al. 1985 and Gilland 1991). This optimization may be done parametrically for a fixed value of efficiency, with specific impulse and power level the parameters to be optimized. In addition, power level is normalized by payload mass, so that any payload may be assumed.

For mission performance comparisons, the results of the NASA 90-day Study (NASA 1989) for a hydrogen/oxygen (H/O) lunar cargo vehicle using an Earth return aerobrake with $20.5 \%$ mass fraction were used. Payload mass delivered to LLO was $58 \mathrm{Mg}$. The chemical/aerobrake vehicle was assumed to be reuseable for 5 missions, one per year. Previous studies of a comparable lunar NEP cargo vehicle have shown a $50 \%$ reduction in initial mass over the course of 5 missions (Hack et al. 1990). In these studies, the retum propellant requirements of the NEP vehicle were found to be small relative to the payload and system mass. Performance comparisons in this study are on a single vehicle basis, which neglects the major benefit of NEP systems: reduced resupply mass.

\section{Mars Cargo}

NEP has often been considered for the Mars Cargo mission (Mason et al. 1989). The reference NEP cargo mission is a one way mission, with the vehicle departing from a Space Station Freedom Orbit of $407.5 \mathrm{~km}$. Mars parking orbit is at Deimos altitude, $20077 \mathrm{~km}$. In heliocentric space, the acceleration of the NEP vehicle is of the same order as the Sun's gravity; therefore, no approximation of constant $\Delta \mathrm{V}$ can be made. Generally, the exact vehicle trajectory must be calculated numerically through a calculus of variations optimization process. A single invariant trajectory parameter has been identified which allows a mission to be approximated for use in system optimization. This approximation can be used to determine system performance with enough accuracy for parametric comparisons (Gilland, 1991).

In the system analysis, the optimum parameters power/payload mass (Pe/MI) and payload fraction ( $\mu$ ) are calculated for a fixed trip time of 600 days, including spiral time, for a range of specific impulse and efficiency values. Mission performance is characterized primarily by payload fraction for the cargo mission, and the sensitivity of this parameter to Isp and efficiency is calculated. Power and initial mass requirements can also be derived based on representative payload masses.

\section{Mars Piloted}

The nature of a round trip piloted Mars mission introduces several additional degrees of freedom into the mission analysis, particularly the optimal balancing of outbound and inbound propulsion requirements. The emphasis upon minimum trip times for this type of mission also constrains the launch date availability compared to the less 
demanding cargo missions. In order to address the sensitivity of a round trip mission to system parameters, a reference opposition- class piloted mission was analyzed for a launch date of 2016, with a 30 day stay time at Mars. Total piloted trip time, defined as heliocentric transit time and Mars stay time, was fixed at 500 days. Earth departure orbit was $407.5 \mathrm{~km}$, and Mars orbit was $20077 \mathrm{~km}$. Payload masses were $124 \mathrm{Mg}$ outbound, $40.3 \mathrm{Mg}$ inbound. Propellant mass for orbital spirals at Earth and Mars are included in the vehicle initial mass; however, piloted trip time does not include spiral time at Earth, as the crew would not be aboard during this phase. A full numerical mission analysis and optimization was performed for a range of specific impulse and efficiency values for a fixed trip time. Two values of specific mass, 5 and $10 \mathrm{~kg} / \mathrm{kWe}$, were initially considered; however, the 10 $\mathrm{kg} / \mathrm{kWe}$ case was not capable of achieving the specified trip time. Power was allowed to vary; A single case was run for a fixed power of $10 \mathrm{MWe}$, which results in a more limited mission capability.

\section{BESULTS}

Lunar Cargo: The lunar cargo mission results are shown in Figures 1 through 6 . Figures 1, 3, and 5 show the optimized vehicle parameters (Isp, Power, and Initial Mass) for a $10 \mathrm{~kg} / \mathrm{kWe}$ vehicle over a range of round trip times. Each curve represents a constant thruster efficiency. Figures 2,4 , and 6 show similar results for a $20 \mathrm{~kg} / \mathrm{kWe}$ total system specific mass. The initial mass of the comparable chemical/aerobrake system is shown as a horizontal line for comparison.

The lunar cargo mission studies assess the sensitivity of mission performance to $\alpha$, Isp, and efficiency. System $\alpha$ plays a fundamental role in determining mission capability, as seen in Figures 1 and 2. Increasing $\alpha$ leads to lower values of Isp in order to perform a mission in a given trip time. Propellant and power system requirements increase accordingly, resulting in poorer vehicle performance. As an example, for a round trip time of 400 days and an efficiency of 0.4 , the $10 \mathrm{~kg} / \mathrm{kWe}$ system is found to operate best at an Isp of 4600 seconds, compared to a value of 2800 seconds for a $20 \mathrm{~kg} / \mathrm{kWe}$ system. A $10 \mathrm{Mg}$ penalty in vehicle mass is also imposed. This difference in performance increases with decreased trip time, until the $20 \mathrm{~kg} / \mathrm{kWe}$ system reaches the chemical/aerobrake value at a trip time of $\sim 220$ days, compared to a value of 120 days for the $10 \mathrm{~kg} / \mathrm{kWe}$. Efficiency is found to play an important role in vehicle performance at values of 0.6 or less, while gains in efficiency to levels greater than 0.6 have a less drastic effect on performance. Even a thruster efficiency of 0.4 allows cargo mission performance superior to the chemical/aerobrake system. For reasonable efficiencies, optimum Isp values fall in the 2000 to 7000 second range, depending on specific mass and trip time. Corresponding power requirements range from 1 to $8 \mathrm{MWe}$. Efficiencies and Isp values in the preferred ranges could be accomplished using either MPD or ion thrusters, with propellant determining the suitable ion thruster choice. The MWe power requirements indicate the need for higher capacity nuclear power systems and thrusters.

Mars Cargo: Approximate Mars cargo system/mission analyses are shown in Figures 7 and 8 . The mission analyzed is a 600 -day total trip time mission, using a $10 \mathrm{~kg} / \mathrm{kWe}$ NEP system operating at 4000 and 7000 seconds Isp over a range of efficiencies from 0.25 to 0.8 . Results are shown in a normalized format; Figure 7 shows the vehicle initial mass variation with efficiency, normalized by the payload mass, with an estimated chemical/aerobrake payload fraction shown for comparison. The corresponding power requirements are shown in Figure 8, also normalized by payload mass. The dependence upon efficiency is reduced in this mission due to the relaxed constraint on trip time.

Mars cargo mission analyses focussed upon the effects of efficiency and Isp upon mission performance. Specific mass also plays a key role in NEP performance; however, this sensitivity has been explored amply in the literature (Hack et al. 1990). This study has focussed more on the propulsion system sensitivities which affect mission performance. For the Mars cargo mission, as with the lunar cargo, efficiencies of 0.4 or greater are desireable in order to obtain superior mission performance. The effects of Isp are less noticeable except at low efficiencies. The crossing of the two mass ratio lines at low efficiencies is an excellent example of the interchange of effects between Isp and efficiency. This interaction is important to model in system and mission optimization analyscs. It is interesting to note that the desired Isp and efficiency values are similar for both the lunar and Mars cargo vehicles, indicating a possible commonality in thruster system design.

Mars Piloted: Mars Piloted results are shown in Figures 9 through 11 . Only an $\alpha$ of $5 \mathrm{~kg} / \mathrm{kWe}$ was able to 
achieve the 500-day round trip mission. Figure 7 shows the vehicle initial mass variation with efficiency and Isp, with power allowed to vary. Representative chemical/aerobrake and Nuclear Thermal Rocket mission performance are also shown. Figure 8 shows the corresponding power requirements. Figure 9 shows the mission sensitivity of NEP for a fixed power of $10 \mathrm{MWe}$, demonstrating the smaller performance space available.

Piloted Mars missions show a more dramatic sensitivity to efficiency due to the high energy requirements of the reduced trip time missions. The round trip nature of the mission further intensifies the effects of Isp and efficiency variations. Efficiencies greater than 0.6 are desired in order to significantly reduce system mass compared to other advanced propulsion concepts. At lower efficiencies, power system mass dominates the vehicle. The effects of changing Isp appear primarily in the power requirements, where there is a $50 \%-60 \%$ increase in power requirements for the higher Isp value. By limiting power to $10 \mathrm{MWe}$, the role of efficency in the mission performance becomes more important in that the capability of the system to perform the desired trip time mission is very dependent upon efficiency. In general, the Mars and lunar missions both underscore the desirability for high Isp and efficiency, while identifying some representative operating regimes to serve as goals in technology development. It should also be noted that the $\alpha$ assumed for this study is $5 \mathrm{~kg} / \mathrm{kWe}$, a relatively optimistic value.

\section{CONCLUSIONS}

System and mission analysis results provide some guidance and insight into NEP system and technology needs. Conclusions can be made about efficiency, specific mass, specific impulse, and power requirements for SEI missions:

Efficiency: For both lunar and Mars cargo missions, efficiencies of 0.4 or higher are needed for NEP systems to be competitive with more conventional propulsion systems. The piloted Mars mission, with its greater energy requirements, needs efficiencies greater than 0.6 to compete with other propulsion options.

Specific Impulse: The lunar cargo mission specific impulse requirement depends on trip time as well as both specific mass and efficiency assumptions. Low efficiency and high specific mass values drive specific impulse values lower. Specific impulse values range from 2000 to 7000 seconds. The sensitivity to specific impulse for the Mars cargo mission is seen to be low, except at low efficiency values. Specific impulse values of 4000 or 7000 seconds provide significant reductions in vehicle mass until efficiency drops below 0.4 .

Specific Mass: Sensitivity to specific mass is seen in the lunar cargo vehicle studies. Higher values of specific mass lead to increased sensitivity to efficiency, due to the greater mass impact from increased power. The higher specific mass system is not capable of achieving trip times as short as lower specific mass systems. For example, a specific mass of $10 \mathrm{~kg} / \mathrm{kWe}$ could not be shown for the 500 day piloted Mars mission, as it was incapable of reaching this trip time with a reasonable value of initial mass or power. Lower specific mass values allow increased power and specific impulse to be used for a more efficient propulsion system.

Power. Power requirements are dependent upon mission trip time, payload mass, and difficulty; as well as specific mass, specific impulse, and efficiency. Power requirements for the lunar cargo mission were found to range from $1 \mathrm{MWe}$ to $8 \mathrm{MWe}$, depending on specific mass and trip time. Mars cargo missions carrying hundreds of $\mathrm{Mg}$ of payload, are estimated to require 1 to $10 \mathrm{MWe}$, based on calculations for the 600 day cargo mission. The piloted Mars mission drives power requirements into the tens of MWe.

Technology implications: A possible progression of technology development can be seen over the range of SEI missions. The lunar cargo mission starts with modest efficiency, specific mass, and power requirements. Efficiencies of .4 , specific masses of $20 \mathrm{~kg} / \mathrm{kWe}$, and powers of $1-2$ MWe would be reasonable first steps in NEP system development. Mars cargo mission requirements show significant commonality with the lunar missions for all parameters, indicating the very real possibility for a common lunar/Mars cargo vehicle, operating at approximately $5 \mathrm{MWe}$, with common thruster technologies. Mars piloted vehicles drive technology to the next level, requiring more than $10 \mathrm{MWe}$, with lower specific masses and higher efficiencies, as well. An evolutionary technology development path is therefore evident for both power and propulsion systems. 


\section{Acknowledgement}

This work was performed by Sverdrup Technology for the NASA Lewis Research Center Nuclear Propulsion Office under contract number NAS3-25266.

\section{References}

Auweter-Kurtz, M., H. L. Kurtz, and H.O. Schrade, "Optimization of Propulsion Systems for Orbital Transfer with Separate Power Supplies Considering Variable Thruster Efficiencies," AIAA Paper No. 85-1152, Presented at the

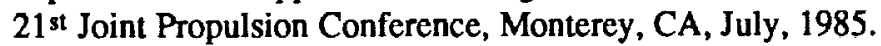

Gilland, J. H., "Mission and System Optimization of NEP Vehicles for Lunar and Mars Missions," International Electric Propulsion Conference Paper No. 91-038, presented at the International Electric Propulsion Conference, Viareggio, Italy, October 1991.

Hack, K. J., J. A. George, J. P. Riehl, and J. H. Gilland, "Evolutionary Use of Nuclear Electric Propulsion," AIAA Paper No. 91-3821, Presented at the Space Programs and Technologies Conference, Huntsville, AL, September, 1990.

Jones, R. M. and J. Scott-Monck, "The Status of Power Supplies for Primary Electric Propulsion in the U.S.A.," in Proceedings of the $17^{\text {th }}$ International Electric Propulsion Conference, International Electric Propulsion Conference Paper No. 84-83, held in Tokyo, Japan, May 1984, pp. 614-629.

Mason, L. S., K. H. Hack, and J. H. Gilland, "Nuclear Electric Propulsion for Mars Cargo Missions," in Proceedings of the Seventh Symposium on Space Nuclear Power Systems, Vol. 1, pp. 32-37., Albuquerque, NM, January, 1989.

NASA, Report of the 90-Day Study on Human Exploration of the Moon and Mars, National Aeronautics and Space Administration, Washington, D.C. November 1989.

Palaszewski, B.A., "Lunar Transfer Vehicle Design Issues with Electric Propulsion Systems," AIAA Paper No. 892375, Presented at the 25th Joint Propulsion Conference, Monterey, CA, July, 1989.

Priest, C., and G. Woodcock, "Space Transportation Systems Supporting a Lunar Base," AIAA Paper No. 90-0422, Presented at 29th Aerospace Sciences Conference, Reno, Nevada, January, 1990.

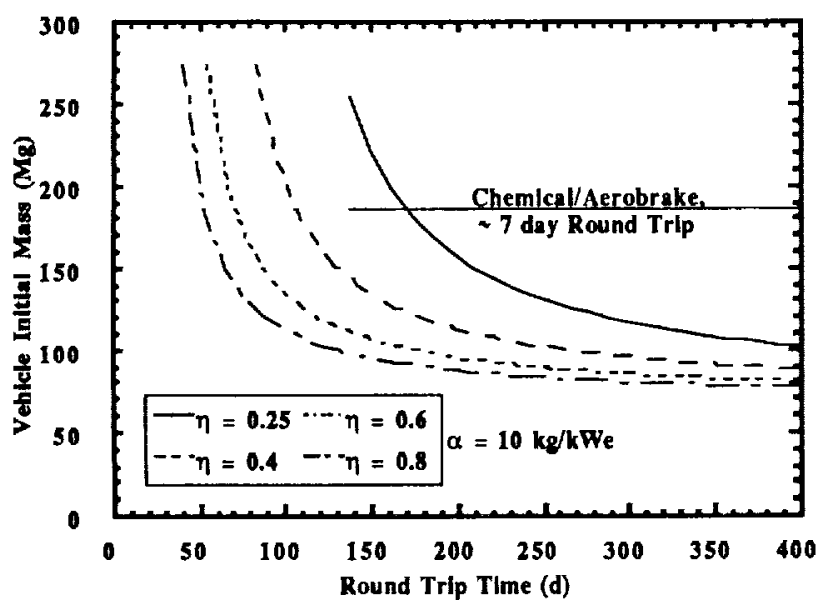

FIGURE 1. Sensitivity of NEP to Thruster Efficiency for the Lunar Cargo Mission, $\alpha=10 \mathrm{~kg} / \mathrm{kWe}$.

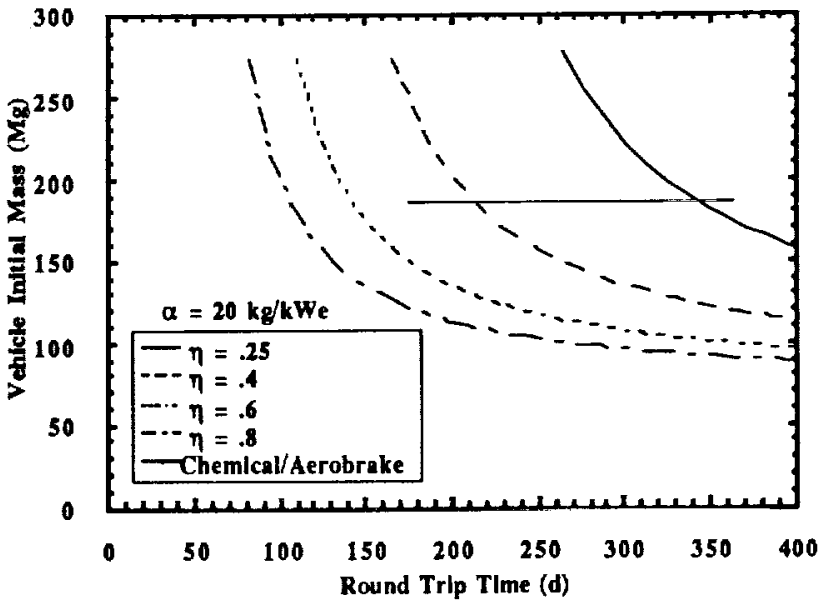

FIGURE 2. Sensitivity of NEP to Thruster Efficiency for the Lunar Cargo Mission, $\alpha=20 \mathrm{~kg} / \mathrm{kWe}$. 


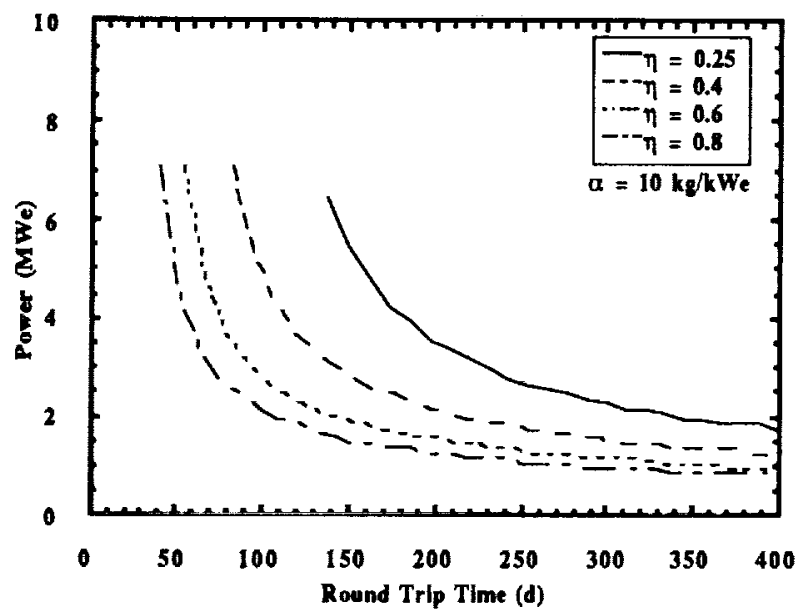

FIGURE 3. Optimum Power Levels for the NEP Lunar Cargo Mission, $\alpha=10 \mathrm{~kg} / \mathrm{kWe}$.

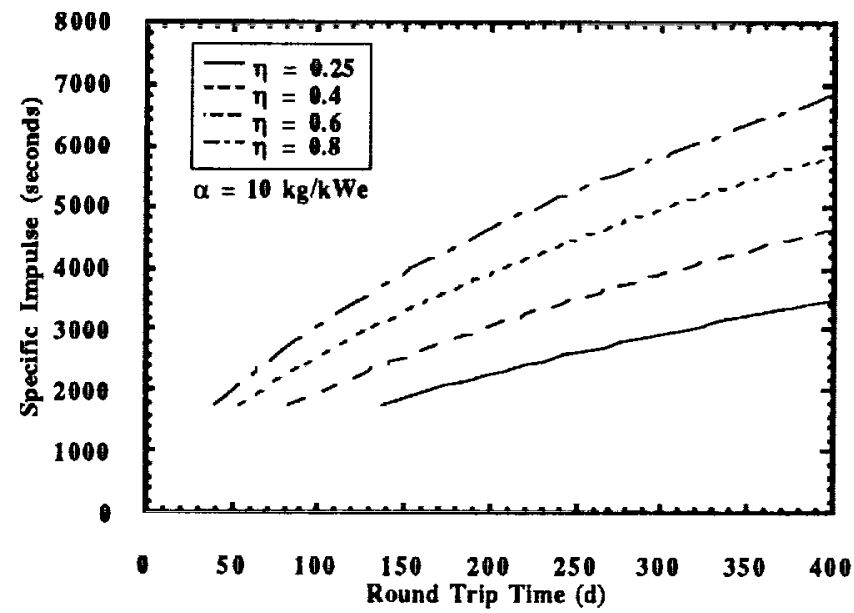

FIGURE 5. Optimum Power Levels for the NEP Lunar Cargo Mission, $\alpha=10 \mathrm{~kg} / \mathrm{kWe}$.

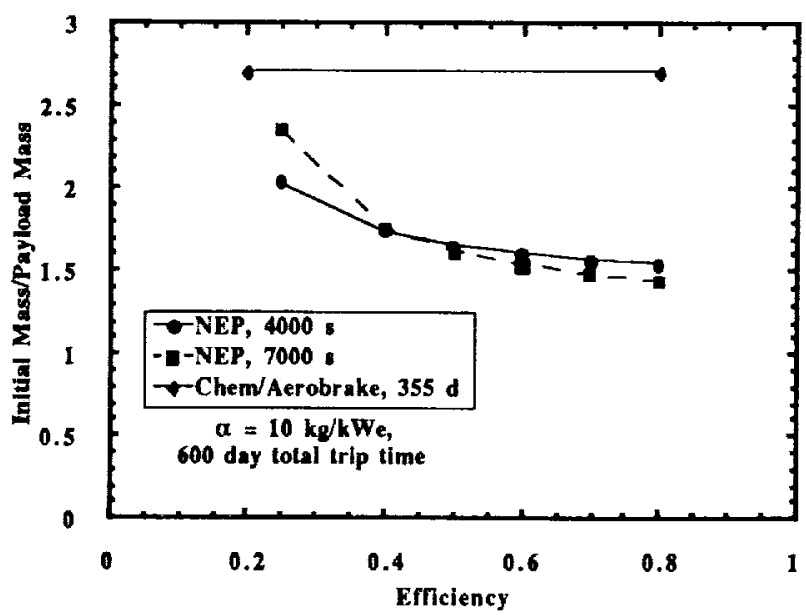

FIGURE 7. NEP Sensitivity to Elficiency, Isp for the Mars Cargo Mission.

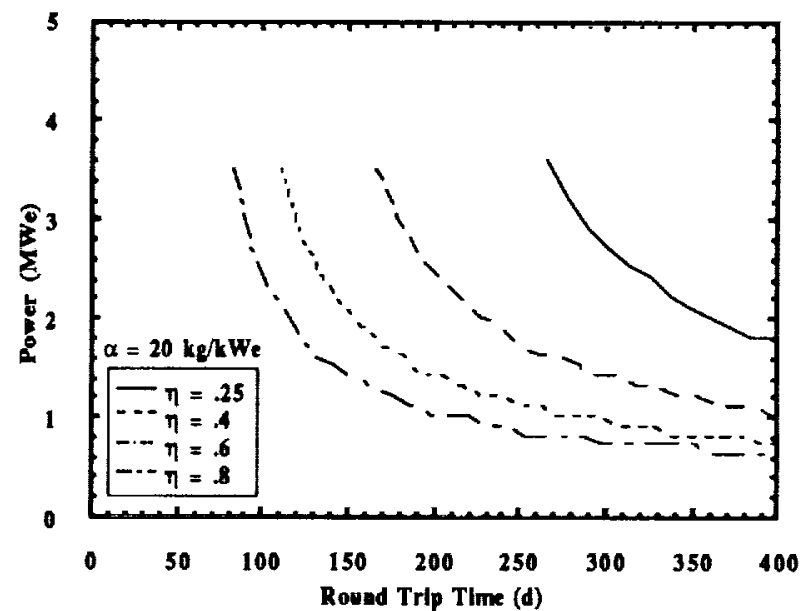

FIGURE 4. Optimum Power Levels for the NEP Lunar Cargo Mission, $\alpha=20 \mathrm{~kg} / \mathrm{kWe}$.

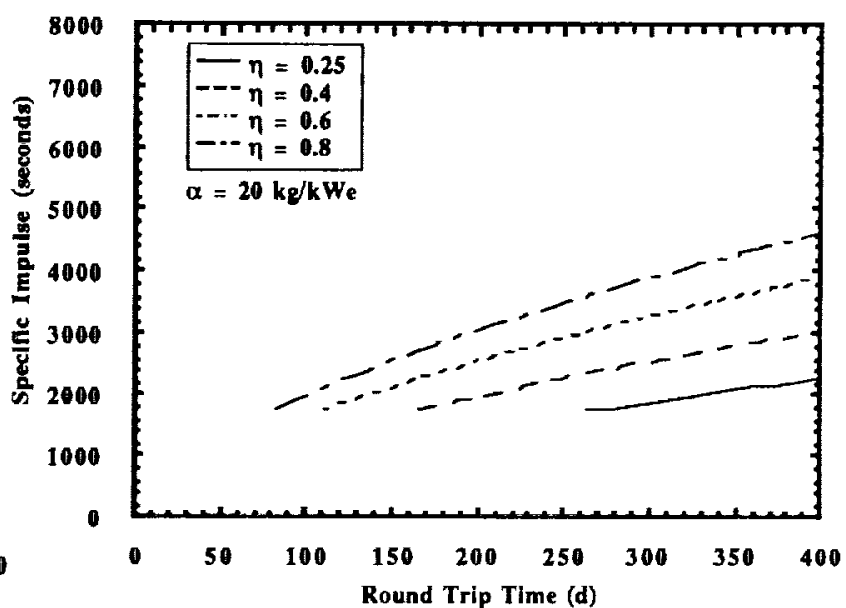

FIGURE 6. Optimum Power Levels for the NEP Lunar Cargo Mission, $\alpha=20 \mathrm{~kg} / \mathrm{kWe}$.

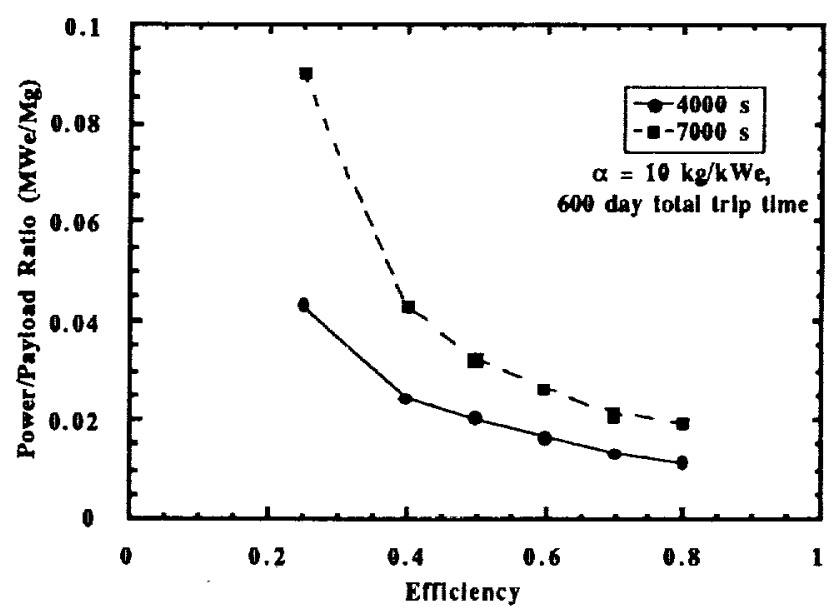

FIGURE 8. NEP Power Requirements for the Mars Cargo Mission, Normalized by Payload Mass. 


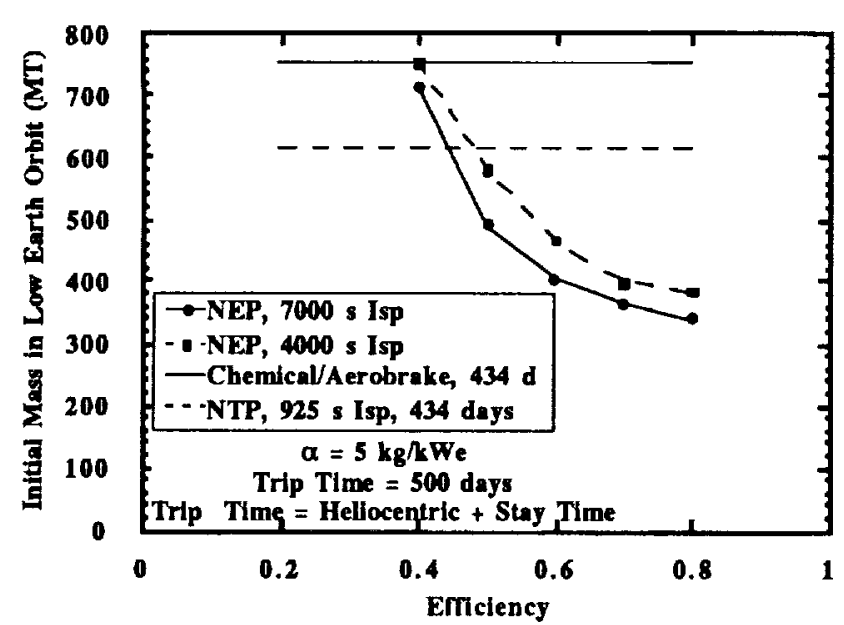

FIGURE 9. NEP sensitivity to Efficiency, Isp for the Mars Piloted Mission. Power varies.

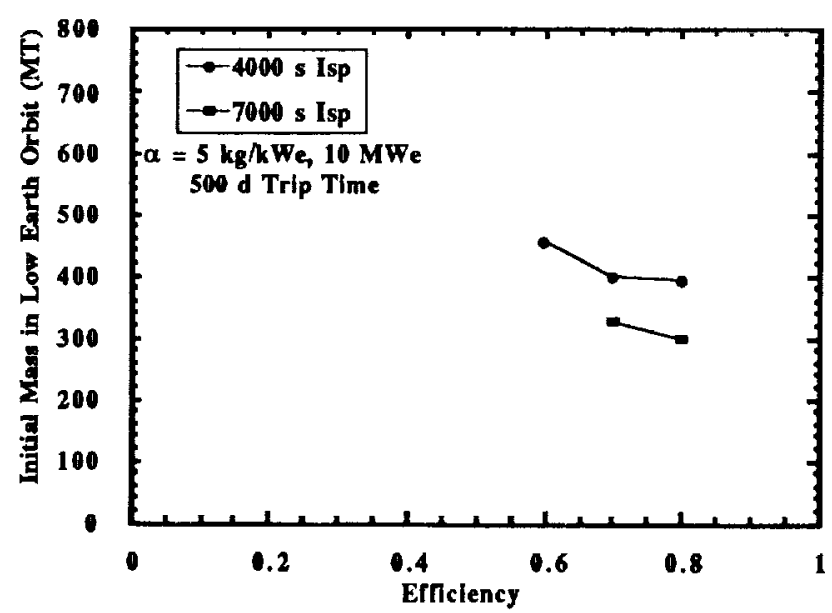

FIGURE 11. NEP sensitivity to Efficiency, Isp for the Mars Piloted Mission, Fixed Power.

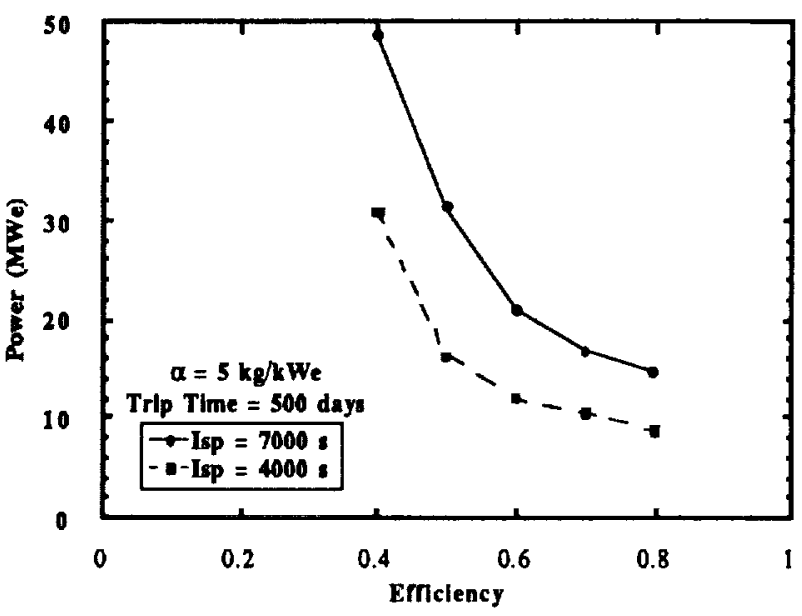

FIGURE 10. NEP Power Requirements for Mars Piloted Mission. 


\section{REPORT DOCUMENTATION PAGE}

Public reporting burden for this collection of information is estimated to average 1 hour per response, including the time for reviewing instructions, searching existing data sources, gathering and maintaining the data needed, and completing and reviewing the collection of information. Send comments regarding this burden estimaie or any other aspect of this collection of information, including suggestions for reducing this burden, to Washington Headquarters Services, Directorate for information Operations and Reports, 1215 Jefferson Davis Highway, Suite 1204, Arlington, VA 22202-4302, and to the Office of Management and Budget. Paperwork Reduction Project (0704-0188), Washington, DC 20503.

\begin{tabular}{l|l|l}
\hline 1. AGENCY USE ONLY (Leave blank) & 2. REPORT DATE & 3. REPORT TYPE AND DATES COVERED
\end{tabular}

4. TITLE AND SUBTITLE

December 1991

Final Contractor Report

WU-None

6. AUTHOR(S)

C-NAS3-25266

James H. Gilland

7. PERFORMING ORGANIZATION NAME(S) AND ADDRESS(ES)

8. PERFORMING ORGANIZATION

Sverdrup Technology, Inc.

Lewis Research Center Group

2001 Aerospace Parkway

REPORT NUMBER

Brook Park, Ohio 44142

E- 6660

9. SPONSORING/MONITORING AGENCY NAMES(S) AND ADDRESS(ES)

10. SPONSORING/MONITORING

AGENCY REPORT NUMBER

National Aeronautics and Space Administration

Lewis Research Center

NASA CR-189059

Cleveland, Ohio 44135-3191

11. SUPPLEMENTARY NOTES

Project Manager, John Clark, Nuclear Propulsion Office, NASA Lewis Research Center, (216) 977-7090

Prepared for the Ninth Symposium on Space Nuclear Systems sponsored by the University of New Mexico, Albuquerque, New Mexico, January 12-16, 1992.

12a. DISTRIBUTION/AVAILABILITY STATEMENT

12b. DISTAIBUTION CODE

Unclassified - Unlimited

Subject Category 20

13. ABSTRACT (Maximum 200 words)

Nuclear Electric Propulsion (NEP) mission performance is strongly affected by system performance. Power and propulsion system specific mass, specific impulse, and efficiency all combine to determine the performance limits for a given mission. Thruster technology determines the specific impulse and efficiency of the system. The effects of these parameters on the mission performance of NEP systems relative to other concepts has been analyzed to give guidance to thruster development goals for a range of missions: Lunar Cargo, Mars Cargo, and Mars Piloted. Mission sensitivities to system parameters are discussed, and technology requirements are identified for each mission.

14. SUBJECT TERMS

Electric propulsion; Mission analysis; Trajectory analysis; Nuclear electric propulsion

17. SECURITY CLASSIFICATION OF REPORT

Unclassified
18. SECUAITY CLASSIFICATION OF THIS PAGE

Unclassified
19. SECURTY CLASSIFICATION OF AESTRACT

Unclassified 